\title{
La Fodina de Aguas Teñidas (Almonaster la Real, Huelva)
}

Juan Aurelio Pérez Macías Universidad de Huelva

Diego GonzÁlez Batanero

Agustín García GonZÁlez

Alejandra Echevarría SÁnchez

Anfora G.I.P.

Recibido: 18/03/2013

Revisado: 20/03/2013
Aceptado: $19 / 04 / 2013$

Publicado: 17/06/2013

\section{RESUMEN}

En este trabajo se presentan los resultados de las intervenciones arqueológicas preventivas realizadas en la mina de Aguas Teñidas (Almonaster la Real, Huelva). Se describen los restos romanos asociados a su explotación, un pequeño escorial de cobre y un edificio de grandes dimensiones, y se estudian los materiales muebles asociados a estos restos, que permiten plantear que la explotación se centró en la primera mitad del siglo I d. C. Como conclusión se propone que Aguas Teñidas representa un modelo de explotación minera muy corriente en las minas de la Faja Pirítica ibérica, un distrito minero en el que sólo las grandes minas de Riotinto, Tharsis, Sotiel Coronada, y Aljustrel continuaron con la producción de metal en la segunda mitad del siglo I d.C. y el siglo II d.C.

\section{Palabras Clave}

Faja Pirítica Ibérica, Mina de Aguas Teñidas, Minería Romana, cobre.

\section{ABSTRAC}

This paper presents the results of archaeological preventive interventions carried out at Aguas Teñidas mine (Almonaster la Real, Huelva). We describe the Roman remains associated with its explotation, a small heaps of copper slag and a large building, and the study of archeological materials associated with these remains (pottery, glass, iron tools, etc.), which allow to state that the operation concentrated on the first half of the first century a.C. In conclusion Aguas Teñidas represent a model mine very common in the mines of the Iberian Pyrite Belt, a mining district in which only large mines of Rio Tinto, Tharsis, Sotiel Coronada, and Aljustrel continued with the metal production in the second half of the first century and the second century a.C.

\section{KEYWORDS}

Iberian Pyrite Belt, Aguas Teñidas mine, Roman Mining, Copper. 
La mina de Aguas Teñidas (Almonaster la Real, Huelva).

Conocemos la minería desarrollada en época romana en los cotos mineros del Suroeste ibérico gracias fundamentalmente a los trabajos de geólogos como J. Gonzalo y Tarín (1888) e ingenieros de minas como I. Pinedo Vara (1963). Sus obras tratan de la geología y de la minería desarrollada en estas minas en época contemporánea, pero la espectacularidad de los restos romanos encontrados durante el laboreo de la segunda mitad del siglo XIX y primera mitad del siglo XX, contribuía a ensalzar el desarrollo industrial que habían alcanzado estas minas en la antigüedad, un argumento sobre la bondad mineralúrgica de sus masas minerales que abría la esperanza para encontrar nuevas zonas no exploradas y explotadas. Esto no era extraño, pues desde fines del siglo XIX el capitalismo europeo había invertido en la puesta en explotación de la mayor parte de estas minas (Rio Tinto Company Limited, Tharsis Sulphur and Copper Company, Societé Française de Pirites de Huelva, Companhia Portuguesa das Minas de Huelva, etc.), y se estaba demostrando que las mineralizaciones no habían quedado agotadas en época romana. Fue el ingeniero francés E. Deligny (1863) el verdadero impulsor de esta fiebre del cobre. Había recorrido la región y se percató de que las mineralizaciones se extendían por las provincias de Sevilla, Huelva, y la región portuguesa del distrito de Beja (Baixo Alentejo), lo que hoy se denomina la Faja Pirítica Ibérica. Abrió el camino para que se fueran formalizando los consorcios que pusieron en explotación estos enormes yacimientos minerales, entre los que enseguida destacaron Tharsis, Sotiel Coronada, Cueva de la Mora, Castillo de Buitrón, São Domingos, y Aljustrel. En Riotinto la explotación había comenzado antes, desde el siglo XVIII, unas veces en manos de arrendatarios y otras por la corona, aunque finalmente fue enajenada a una compañía británica (Rio Tinto Company Limited).

Aunque se habían abierto nuevas posibilidades de beneficio, como el aprovechamiento del sulfuro para la producción de ácido sulfúrico, muy demandado por el impulso que estaba adquiriendo la industria química, el cobre era aún el metal de referencia para alimentar el proceso de electrificación que se llevaba a cabo. Incluso los análisis demostraban que existían cantidades de oro y plata que podían ser aprovechadas, pero por el momento no se conocían procesos que permitieran recuperarlos. $\mathrm{Si}$ se extrajeron algunas cantidades de plata en minerales que presentaban una concentración de este metal en proporciones similares a como se habían explotado en época romana. La mayor parte de la plata rentable de estas minas había sido sistemáticamente explotada en época romana, pero no así el cobre, cuyas reservas tenían todavía la suficiente entidad como para que se desencadenara una verdadera fiebre minera. En estos años de relanzamiento de la actividad minera se va a hacer realidad la frase de "minero de cobre, minero pobre", y comienza la proletarización de las masas de campesinos que acudieron a las minas para mejorar unas condiciones de vida que la industria minera favorecía.

A partir del enorme esfuerzo de la minería decimonónica se pudo ir descubriendo la riqueza arqueológica que atesoraban estas minas, $\mathrm{y}$ a las exposiciones universales de la época se llevaron los materiales e ingenios mineros más interesantes. Las empresas mineras eran consorcios capitalistas que precisaban inversiones, y los hallazgos arqueológicos eran un buen reclamo publicitario para mostrar los rendimientos que podían obtenerse de estas minas. Sin embargo, no todas las minas tenían las mismas posibilidades, los tonelajes de los minerales variaban enormemente de unas a otras.

En este resurgir de la minería contemporánea participó también un pequeño yacimiento de sulfuros, la mina de Aguas Teñidas, situado a escasa distancia de otras minas que habían alcanzado renombre, las de Cueva de la Mora y Monte Romero. La mina de Aguas Teñidas se encuentra en un sector de la Faja Pirítica Ibérica donde se concentran un buen número de masas polimetálicas, muy próximas unas a otras. Entre otras a este conjunto se pueden adscribir las minas de La Joya, LomeroPoyatos, Lancha-Roma, San Telmo, El Carpio, Herrerías de los Confesionarios (Valdelamusa), Cueva de la Mora, Monte Romero, y Angelita, y muy cerca se encuentran también otros yacimientos de fama, las minas de San Miguel y La Zarza-Perrunal (figura 1). Aunque las minas más intensamente explotada de este grupo han sido las minas de San Telmo y Valdelamusa, el resto de las minas alcanzaron fama por sus leyes de cobre (Monte Romero y Aguas Teñidas) y oro (Lomero y Poyatos). La explotación romana fue significativa en Cueva de la Mora, Aguas Teñidas, San Telmo, y la Joya (Pérez Macías, 1998). 

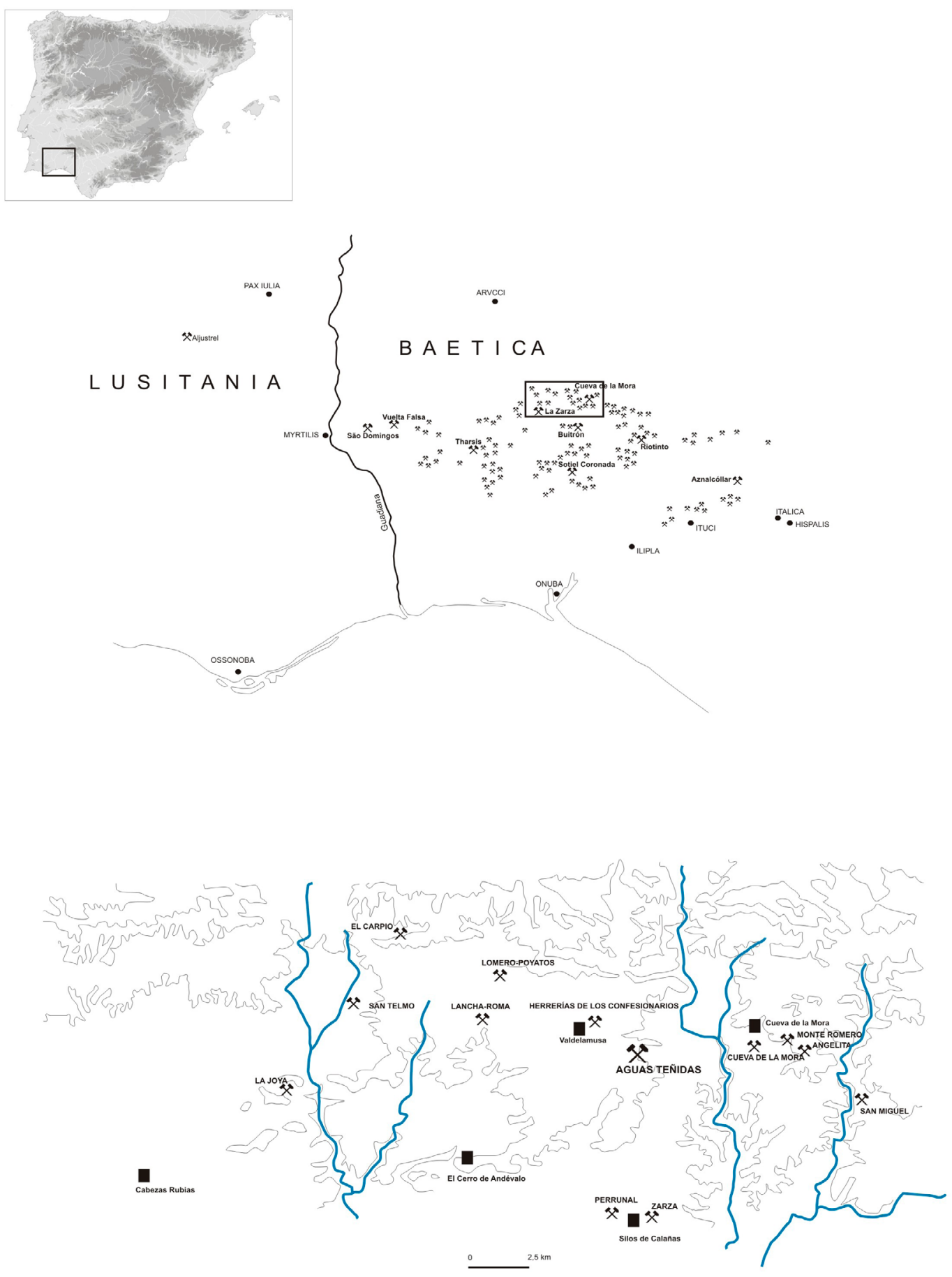

Figura 1. Situación de la Mina de Aguas Teñidas. 
La mina de Aguas Teñidas está formada por varias concesiones, Calañesa, Bella Holandesa y Aguas Teñidas. Los primeros trabajos de exploración se realizaron a partir del informe del ingeniero Arthur Penelet, y en 1883 se constituyó la sociedad minera Compagnie de Cuivre de Aguas Teñidas, que desde 1886 realizó labores de explotación en Aguas Teñidas y la apertura de la Corta de Confesionarios en Valdelamusa.

Al no alcanzarse un óptimo rendimiento, en 1886 se traspasaron sus propiedades a una nueva empresa, la Societé Française des Pyrites de Huelva. Esta sociedad explotó también las minas de El Perrunal, Lomero-Poyatos y el Carpio. En las concesiones del grupo Aguas Teñidas y Herreritos se trazan algunos pozos de exploración, pero solo se encontraron minerales completos.

Dadas las dificultades de tratamiento de estos minerales, en 1916 se arrendaron las concesiones de Calañesa y Bella Holandesa a una compañía anglofrancesa, The Huelva Copper and Sulphur Mines Limited, que ya explotaba desde 1904 las minas de Angelita, Monte Romero, y Cueva de la Mora, donde construyó una fundición. Desde 1922 la fundición solo se alimentó del laboreo intensivo de la concesión Calañesa de Aguas Teñidas, y hasta 1933 se llegaron a tratar unas 600.000 toneladas de mineral de cobre con unas leyes medias de $5 \% \mathrm{Cu}$. Las leyes de sus minerales eran ricas en general, y se han considerado unas medias de $7 \% \mathrm{Cu}$, pero también eran abundantes los tenores de 5 y 6\% Cu. En 1925 se arrancaban unas 100 toneladas de mineral al día, y la compañía tenía a su cargo unos 240 obreros, alojados en el poblado de Valdelamusa, donde Huelva Copper había construido oficinas, carpintería, almacenes, una cooperativa, y una casa dirección. La fundición de Cueva de la Mora, con hornos de cuba Water-Jaacket y convertidores Bessemer, producía 2.200 toneladas de cobre blíster al año, con una ley de $99,00 \%$ de $\mathrm{Cu}$. La caída de los precios del cobre ese año obligó a la paralización de las actividades. El Sindicato Minero de Huelva intentó mantener la explotación, pero tuvo que abandonar el intento un año más tarde. En estos años Huelva Copper había centrado sus trabajos en las concesiones de Calañesa y Bella Holandesa.

Los primeros datos geológicos de estas mineralizaciones se deben a J. Gonzalo y Tarín (1888), quien consideró que los afloramientos de la mineralización se extendían sobre una franja de terreno de $5 \mathrm{~km}$ de largo y $240 \mathrm{~m}$ de ancho, en los que se encontraban cuatro indicaciones de masas de sulfuros ricas en cobre. Defendía la importancia de tales indicios, pero la explotación moderna sólo pudo detectar la mineralización gracias a los pozos antiguos (romanos), la mayor parte atorados, y por los escoriales que existían junto a ellos. La corrida de la masa pudo seguirse por unas hondonadas largas y estrechas que seguían el sentido de la estratificación. De las cuatro indicaciones del yacimiento del Barranco de Aguas Teñidas, la zona más intensamente explotada fue la septentrional, donde se encuentran la mayor parte de los trabajos romanos, entre ellos un pozo inclinado que al desatorarlo todavía conservaba en excelente estado de conservación toda la entibación. En el resto de las indicaciones de la mineralización destaca la zona número 3 , en la que se encontró un pozo antiguo atorado en su mayor parte, y sobre la parte más meridional, en la zona número 4 , se localizaron tres pozos antiguos y algunas excavaciones superficiales. Como testimonio de la explotación romana se descubrieron también diferentes restos de entibaciones de ejecución muy cuidada, lo que le llevó a catalogar esta minería como una explotación muy esmerada. Junto a las entibaciones romanas se recogieron algunas muestras de calcosina, que demostraban que el laboreo romano estuvo destinado al minado de minerales de cobre de alta concentración de la zona de enriquecimiento supergénico. Las muestras tomadas en estos trabajos romanos arrojaron una riqueza de $7,82 \% \mathrm{Cu}, 179$ gramos de plata y dos gramos de oro a la tonelada. En los sulfuros se presentaban también piritas y aglomerados discontinuos de calcopirita y blenda.

Los escasos datos de su geología que aporta I. Pinedo Vara (1963) nos señalan que la masa se encontraba empaquetada entre pizarras y forma una estructura de tendencia filoniana con escasa e irregular potencia, que se delata al exterior por pizarras y cuarzos impregnados de óxidos de hierro.

\section{LA ACTIVIDADES ARQUEOLÓGICAS PREVENTIVAS EN Aguas TeÑidas.}

$\mathrm{Al}$ descubrirse otra masa de sulfuros más al Este de las anteriores, entre 300 y 700 metros de profundidad, la mina ha recuperado su actividad en el año 1985. El nuevo yacimiento de sulfuros masivos presentó en los sondeos unas leyes de $0,8 \% \mathrm{Cu}$, $7,1 \% \mathrm{Zn}$ y $1,5 \% \mathrm{~Pb}$. Las campañas de exploración y sondeos desde esa fecha han logrado definir la envergadura del nuevo yacimiento, una longitud al 
menos de $2800 \mathrm{~m}$ en dirección Este-Oeste, y una potencia que alcanza en algunos lugares los $110 \mathrm{~m}$. Esta nueva masa, de origen vulcano sedimentario como todas las de la Faja Pirítica Ibérica, encaja en tufitas, pizarras y lavas a techo, y riolitas a muro. La masa está formada por sulfuros de cinc (esfalerita), sulfuros de cobre (calcopirita) y sulfuros de plomo (galena). Por debajo de los sulfuros masivos se sitúa una mineralización de tipo stockwork, con una importante riqueza en minerales de cobre, que se ha investigado en $500 \mathrm{~m}$ aproximadamente. La compañía que explota esta nueva masa de sulfuros polimetálicos complejos, Minas de Aguas Teñidas S.A. (Matsa), realiza la explotación por contramina, por un sistema de cámaras de 30×20×60 m, con relleno de pasta, y extracción mediante grandes rampas de acceso (Santa Eulalia y Santa Bárbara). Actualmente se procesan unas 1,7 millones de toneladas al año para la producción de concentrados de mineral cobrizo y polimetálicos.

La puesta en marcha del nuevo proyecto minero por la compañía Matsa llevó consigo la construcción de instalaciones industriales, y se fijaron una serie de cautelas arqueológicas que garantizaran la conservación del patrimonio mina, para que en su caso fuera documentado e investigado antes de su afección por los trabajos de minería. Entre estas instalaciones se encontraba la planta de tratamiento del mineral, que motivó la realización de una primera intervención arqueológica de carácter preventivo en 2006, para localizar posibles yacimientos arqueológicos que pudieran ser afectados por estas obras. Para ello se programó una Prospección Arqueológica Superficial en el área donde iba a ser construida la planta de tratamiento y el depósito de minerales estériles, y un Control de Movimientos de Tierra durante la realización de las obras.

La información sobre los restos romanos de la mina de Aguas Teñidas no era mucha, pues salvo las menciones de J. Gonzalo y Tarín e I. Pinedo Vara, la mina sólo había merecido la atención por nuestra parte (Pérez Macías, 1998), documentándose desde ese momento el escorial romano, cuyo análisis demostraba que la mina estuvo en explotación en época romana para la producción de cobre. El escorial no tenía las proporciones de los de otras minas, pero en el conjunto de las minas de esa área fue la segunda mina en volumen de producción después de Cueva de la Mora, en la que la minería romana alcanzó mayores rendimientos en plata y cobre. En otras minas cercanas, como Herrerías de los Confesionarios, Angelita o Monte Romero la explotación romana no fue tan continuada como para que se formara un definido vacíes de escorias. Debido a su escasa entidad el escorial romano de Aguas Teñidas pasó inadvertido en otros trabajos de estudio de estas minas, como la Exploración Arqueometalúrgica de Huelva (Blanco y Rothenberg, 1980). No obstante, la mina presentaba todavía un buen potencial arqueológico, aunque en estas prospecciones anteriores al proyecto Matsa no se identificaran restos del asentamiento romano, del que no quedaban huellas aparentes por la inexistencia de materiales constructivos o de otros materiales de cronología romana en las inmediaciones del escorial romano. Este asentamiento podía encontrarse oculto bajo las escombreras de materiales generados por las explotaciones de la segunda mitad del siglo XIX o comienzo de siglo XX.

Durante la prospección arqueológica superficial y el control de movimientos de tierra no se registraron evidencias arqueológicas en la zona afecta$\mathrm{da}$, y se pudo verificar que estas obras no afectaban al escorial romano de cobre, que se definió con seis puntos de coordenadas Utm para favorecer su conservación. A partir de esta delimitación se estimó que ocupaba una extensión de unos $6115 \mathrm{~m}$ cuadrados y que en algunos puntos alcanzaba una potencia de unos $30 \mathrm{~cm}$ (Romero Bomba y Rivera Jiménez, 2010).

Con estos precedentes, en el año 2011 se ha realizado una nueva intervención ante la ampliación de las instalaciones de la compañía Matsa. Esta segunda intervención tuvo como objetivo ofrecer un diagnóstico sobre la existencia de restos arqueológicos en el subsuelo, evaluar el impacto de las obras y proponer medidas correctoras. Se planteó en primer lugar una delimitación planimétrica de las zonas de dispersión de restos arqueológicos dentro de la concesión minera, con propuestas de intervención en las zonas catalogadas para la correcta documentación de los restos, y la intervención arqueológica se realizó en dos fases.

La primera fase consistió en una Prospección Arqueológica Superficial del área que se vería afectada por el proyecto de obras y del entorno de la mina, con la finalidad de obtener una visión general de la zona, y la realización en segundo lugar de una serie de sondeos mecánicos en el área de escoriales romanos del Barranco Herrerito, en los que se pretendía documentar la potencia y la posible estratigrafía de los mismos. 

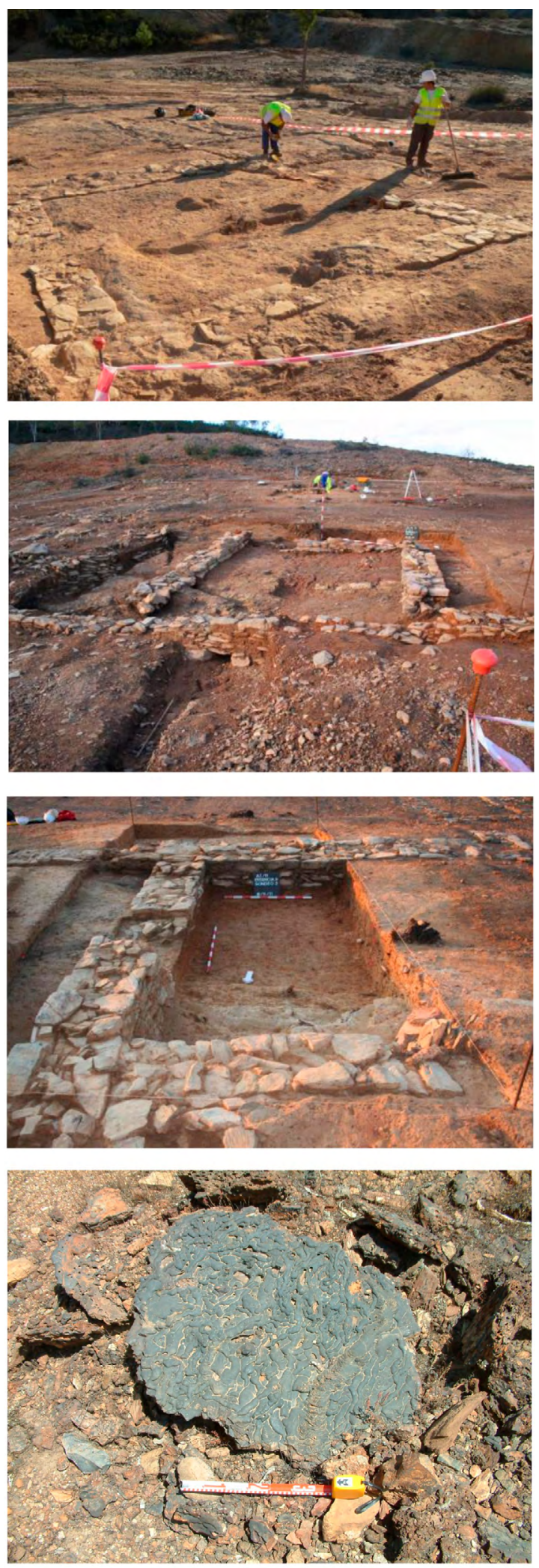

Figura 2. Intervención Arqueológica en Aguas Teñidas: 1, Corte 1; 2, Sondeo 1; 3, Sondeo 2; y 4, Lupia de escoria romana del Escorial 2.
La prospección arqueológica superficial identificó cuatro zonas con vertidos de escorias de época romana, siendo especialmente significativas la zona de escoriales 1 y 2 (figura 2: 4), ya catalogados en los trabajos anteriores (figura 3 ).

Los sondeos mecánicos se plantearon como cuatro zanjas junto a estos dos escoriales romanos (figura 3). La Zanja 1 se trazó en el escorial número 1 , con una dirección E-O $270^{\circ}$, junto a un pequeño barranco que discurre perpendicular al Barranco de Herrerito. La Zanja 2 se planteó en el límite Este de este mismo escorial, con una orientación de S-N $355^{\circ}$ y unas dimensiones de 36,60 por $3,10 \mathrm{~m}$. La Zanja 3 se situó en la zona Oeste del escorial número 2, atravesándolo en una dirección SE-NO, con unas dimensiones de 23 por $2 \mathrm{~m}$. Y la Zanja 4 fue una pequeña limpieza mecánica al Sur de la zanja 1, con unas dimensiones de 14 por $5,30 \mathrm{~m}$, abierta para descartar la existencia de estructuras en la zona. También se realizaron dos perfiles en una nueva zona de escorias identificada en la prospección arqueológica superficial (escorial 3), ubicada en el comienzo del Barranco de Herrerito, de resultados negativos en cuanto a su sucesión estratigráfica.

Además, con el fin de delimitar el Escorial 2 se realizó una limpieza superficial que se denominó Corte 1 (figura 2:1), con unas medidas de $7 \mathrm{~m}$ por 6 $\mathrm{m}$. Durante esta limpieza comenzaron a detectarse estructuras de habitación o trabajo, y para poder definir mejor el carácter de las estructuras aparecidas se decidió ampliar la limpieza mecánica en los lados Norte, Este y Oeste del Corte 1. Todo el nuevo área de limpieza superficial fue denominada Corte $1 \mathrm{~A}$, y en él se fueron identificando y registrando las diferentes unidades estratigráficas constructivas y un número de espacios o estancias que quedaban delimitadas por las mismas.

Ante la aparición de estos restos constructivos de época romana se programó una segunda fase de intervención. El arqueólogo inspector de la Delegación de Cultura de la Junta de Andalucía en Huelva, decidió que se realizara una segunda fase de intervención a fin de obtener la planta lo más completa posible de estas estructuras. La intervención consistió en la realización de dos sondeos estratigráficos y nuevas limpiezas mecánicas y manuales (figura 2: 2 y 3). Uno de estos sondeos se sitúo en la parte Sur (Sondeo 1), con unas medidas de 6 por $6 \mathrm{~m}$, sobre cuatro estancias bien delimitadas por unidades estratigráficas murarías, y otro en la parte Norte 
(Sondeo 2), con unas medidas de 8 por $3 \mathrm{~m}$, sobre otras tres estancias bien definidas por sus unidades constructivas.

En resumen, en el transcurso de las intervenciones en la zona del Corte 1A se han registrado un total de 40 estructuras murarías que forman parte de un solo edificio relacionado con la explotación minera de época romana. Del total de estas estructuras solo han sido excavadas 10 de ellas en el Sondeo 1 y
Sondeo 2, el resto únicamente fueron delimitadas en su desarrollo superficial.

Finalmente, tras la topografía de detalle de todas las estructuras, se procedió al soterramiento con la protección de un geotextil especial de mayor grosor, que se cubrió con una capa de arena limpia de río con unos $10 \mathrm{~cm}$ de espesor, y sobre ella otra capa de tierra vegetal procedente de la limpieza mecánica y de los sondeos estratigráficos.

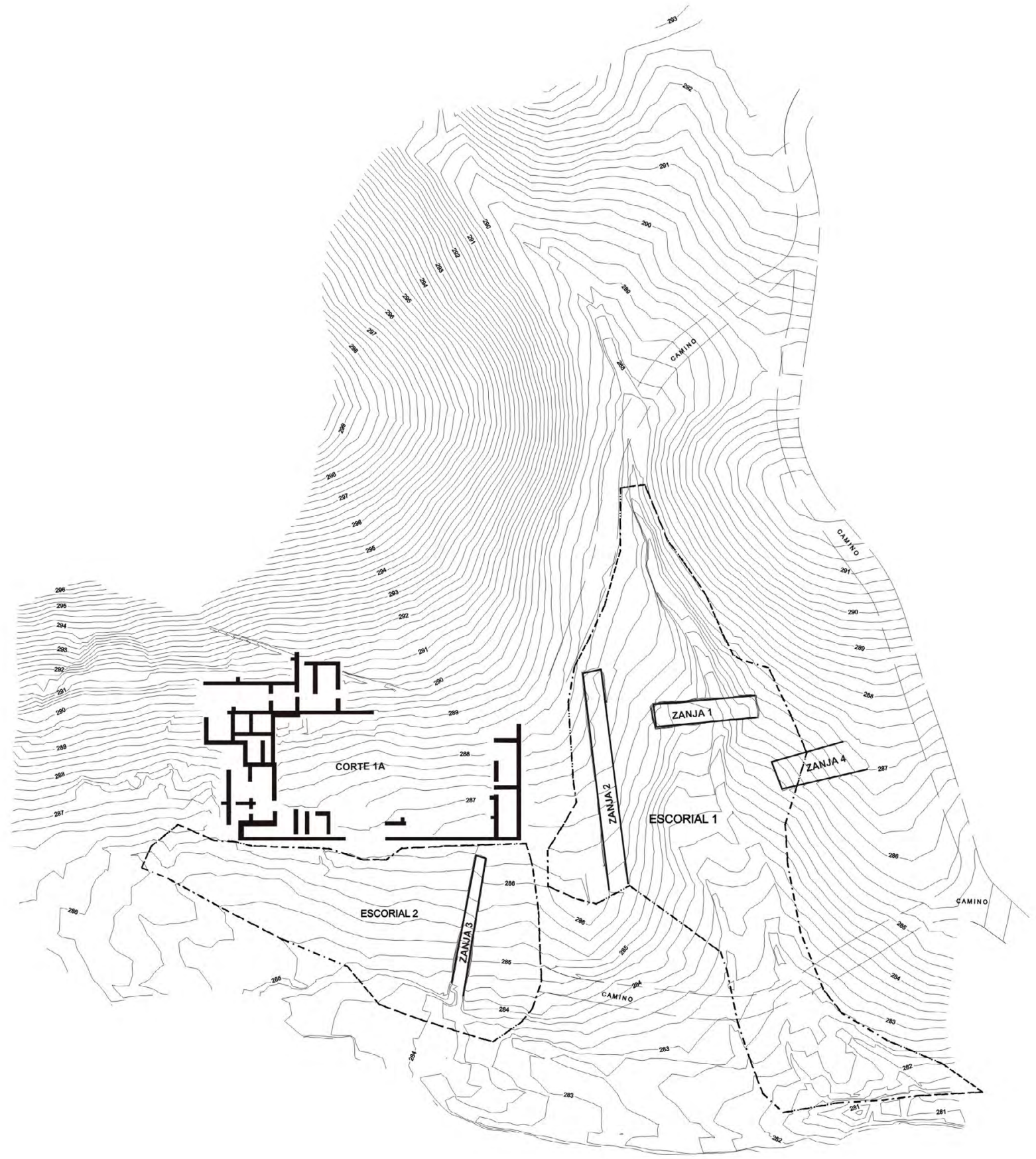

Figura 3. Situación de los escoriales, cortes y edifico de Aguas Teñidas. 
La Statio Minera de Aguas Teñidas.

Aunque no ha podido excavarse totalmente el edificio, se ha puesto al descubierto en su mayor parte (figura 4). Se encontraba arrasado desde época, ya que en algunas zonas los muros no tienen continuidad por haber sido destruidos para aprovechar los materiales o por la propia erosión posterior al abandono. La limpieza superficial ha puesto al descubierto una edificación de planta rectangular con unas dimensiones aproximadas de unos 51 metros de longitud y 31 metros de anchura.

Para su análisis hay que partir en primer lugar de su situación. Se encuentra rodeado en dos de sus lados por los escoriales de cobre, es decir el tratamiento metalúrgico de los minerales se llevaba a cabo en el exterior del edificio, donde se fueron acumulando incluso las escorias. En este sentido conviene señalar que la única entrada/salida del edificio se sitúa precisamente en esta zona en la que se encuentra el escorial, que como es corriente en las escombreras de escorias de época romana se extienden siempre que es posible junto a un cauce de agua, en este caso el Barranco de Herrerito. Parece evidente que la funcionalidad del edificio está relacionada con la minería y tratamiento de los minerales, ya que el último paso de la producción metálica que se llevaba a cabo a pie de mina, la obtención de lingotes de cobre que pudieran exportarse, se desarrollaba en el exterior de este edificio.

Conservamos muy pocas estructuras de reducción de época romana porque los hornos eran destruidos para recuperar el metal del crisol situado en la solera del horno, y lo más que puede detectarse de ellos son los hoyos de sangrado de las escorias o las paredes de arcilla refractaria que formaron las cámaras de reducción. Estos hornos eran capaces de resistir hasta unas diez operaciones de carga para que se obtuviera un buen régulo de cobre, y de ahí que las lupias de escorias que se encuentran en el escorial alcancen el metro de longitud. Por otro lado, no importaba que la fundición de los minerales se efectuara junto a las paredes del edificio, a pesar de las molestias que podían causar la combustión de minerales sulfurosos, que desprendían gases que podían afectar a la respiración. En el poblamiento romano de Aguas Teñidas no se habían diseñado áreas de vivienda y almacenamiento apartadas de las zonas nocivas de tratamiento de minerales, todos los trabajos se concentraron en esta edificación y en sus exteriores se llevaban a cabo las labores de trata- miento metalúrgico. No quedan restos de zonas de tostación y calcinación del mineral en las limpiezas realizadas en las zanjas de comprobación, por lo que parece que este primer paso no se efectuaba en la zona donde se reducía el mineral, en las zonas de escorial ni en las inmediaciones. A pesar de la riqueza de cobre de los minerales de Aguas Teñidas la calcinación de los minerales era precisa para que estos pudieran reducirse posteriormente en metal con la adición de fundentes de sílice y óxidos de hierro, que eliminaban los elementos no deseados de la ganga al separarlos en una fase de silicato de hierro (fayalita, escoria).

Una característica de este edificio es que se va rebajando el substrato geológico sobre el que se asienta, de pizarra, para ir ubicando las distintas estancias, aterrazando de este modo la pendiente en los suelos por estar construido en una superficie inclinada que termina en los escoriales, situados en la margen del Barranco Herrerito.

Para poder determinar áreas funcionales de la edificación hemos dividido la estructura en una serie de sectores, el espacio abierto de corral o patio (A), el testero Este (B), la zona Sur (C), el área Oeste (D), y la parte Norte (E). En las zonas D y E son las que tienen una mayor compartimentación de los espacios (figura 4).

$\mathrm{La}$ arquitectura del edificio está presidida por un área descubierta central (A), a la que se abre un vano desde el escorial. Esta zona de corral (cohors) tiene unas dimensiones aproximadas de $36 \mathrm{~m}$ de largo por $16 \mathrm{~m}$ de ancho, más de un tercio de la extensión total del edificio (figura 4). Aunque no ha podido excavarse, la funcionalidad de este espacio abierto puede relacionarse con la entrada de partidas de mineral, combustible, y fundentes para el proceso de fundición, y con todas las tareas de carga y descarga que ello conllevaba.

El espacio cerrado delimitado por el edificio era también una forma de mantener a buen recaudo el mineral que procedía del interior de las galerías, puesto que en las leyes de Aljustrel se indica que había que salvaguardarlo para que no se produjeran hurtos nocturnos (VIP II, 10). De esta forma el mineral podía ser amontonado en el patio, pero en el estadio en el que ha quedado la excavación de esta estructura, con sólo la limpieza superficial para delinear la trayectoria de las cabezas de los muros, las posibilidades para identificar estas áreas de apiles de mineral se reducen. 
En el ala Este (B) se disponen dos estancias de planta rectangular (21 y 22), con los lados mayores con orientación Norte-Sur, y de lo conservado delante de ellas arrancan dos pequeños muros perpendiculares que no cierran, y forman espacios adosados a ellas en batería. Los módulos de estas estancias son idénticos, de 3 por $7 \mathrm{~m}$ (figura 4). Tampoco ha podido exhumarse al completo todo este lado Este del edificio, pero la duplicidad del modelo de estancias documentada es un argumento a favor de que todo este ala estaría formada por un mismo módulo de habitaciones con un espacio bipartito delante de ellas formado por dos muros transversales.

Estas estructuras recuerdan extraordinariamente a una de las partes de la officina metalúrgica de Azinhal en Aljustrel (Cauuet, Domergue, Dubois, Pulou, y Tollon, 1999). En este caso se conservaban todavía los restos de los materiales tratados, cenizas de piritas producto de la calcinación al aire libre de los minerales. Es un tipo de estructura de tostación que, como han demostrado las investigaciones de la Universidad de Toulouse, continuaron en uso hasta bien entrada la Edad Moderna, según muestran los ejemplos aportados por G. Agrícola. Coincide con esa estructura de Azinhal una habitación rectangular adosada a uno de los muros de cierre del edificio, con unos pequeños muros transversales a ella, dos en cada estancia, que nos delimitan a su vez otros dos apartados, uno de ellos, el que no tiene comunicación con la estancia rectangular que lo antecede, donde se llevaría a cabo la tostación de mineral. Tal como hemos propuesto después de los últimos trabajos en este taller metalúrgico de Azinhal (Pérez, Martins, Bustamante, y Lagares, 2012), se diferencian de este modo tres ámbitos, uno cubierto $\mathrm{y}$ cerrado formado por la estancia rectangular, y dos abiertos por delante de ella, uno donde se calcina el mineral, que no tiene comunicación con la estancia cerrada, y otro donde se estría el resultado de la tostación para seleccionar los núcelos de óxidos que pasarían a la segunda operación de tratamiento, la reducción, que como hemos indicado anteriormente se realizaba fuera del edificio. La estancia cerrada se comunica por un estrecho vano con esta área de selección de óxidos que se recogían para la fundición. Es una habitación cerrada y cubierta porque el almacenamiento de estos materiales evitaría que estuvieran en contacto con la atmósfera y sobre todo para que no pudieran ser afectados por el agua de lluvia, pues al ser los minerales solubles podía disminuir la ley en cobre de los mismos. La estrechez del vano entre la zona de estriado y la de almacenamiento, como también sucede en nuestro sector B, evitaría la entrada de humos sulfurosos y su concentración en el interior de la estancia.

En otros asentamientos mineros de Sierra Morena se han estudiado también edificios en los que predominan estos muros paralelos formando pequeños espacios en batería, como sucede en el asentamiento de Valderreprisa en Ciudad Real (Fernández y García, 1993), donde se han interpretado como almacenes. Son, al igual que el edificio que estamos describiendo, instalaciones presididas por un patio abierto central, de planta aproximadamente rectangular, y con esos muros en batería en uno o varios testeros de la edificación. En nuestra opinión nos encontramos en edificios que siguen de cerca el modelo del taller de tostación de Azinhal en Aljustrel, cuyos restos metalúrgicos no dejan lugar a dudas de que eran compartimentos de tostación. Ya hemos tenido ocasión de comentar que este mismo modelo de hogares de tostación perduraron a lo largo de la Edad Media (Pérez, Martins, Bustamante, y Lagares, 2012), como es patente en los muros de tapial de los escoriales del asentamiento islámico de Saltés (Bazzana y Trauht, 2005).

En el lado Sur (C) no se han localizado estancias tan definidas (figura 4). Esta zona está dividida en dos por el vano que da acceso al escorial, y en la parte Sureste el muro de cierre no tiene adosada ningún tipo de estructura. Desconocemos si ello se debe a que la limpieza superficial no ha rebajado tanto como para descubrir posibles habitaciones o si, como parece más probable, era un espacio libre de compartimentos. En la zona Suroeste pueden distinguirse dos sectores, uno que se encuentra adyacente al vano que da acceso al escorial y otro que forma una de las esquinas del edificio con el testero Oeste.

En la zona Sureste quedan restos de un muro con otros transversales, que recuerdan la forma de las estructuras de la zona B (figura 4). La existencia de varios espacios de tostación puede explicarse con el sistema de tratamiento de los sulfuros, en los que difícilmente se alcanza un producto apto para la fundición después de una sola tostación. Estas operaciones son más eficaces cuando menos cantidad de sulfuro tienen los minerales, y es claro que sería menos complicado el tratamiento de una calcosina, un sulfuro secundario de cobre, que una calcopiritas o cubanita, sulfuros de cobre y hierro. A veces era precisa más de una operación de tostación 
hasta conseguir un buen óxido que pudiera tratarse en fundición, e incluso de estas tostaciones podían obtenerse matas de cobre fácilmente fusibles. En la obra de G. Agricola (1556) estos hogares de tostación aparecen formando series de tres, en otras ocasiones aparecen aislados, y su clasificación nos aclara que en estos hornos se trataban los minerales que salían de la mina previa trituración y los que habían sido tratados en otras operaciones de tostación (fornax in qua venae excoquuntur), unos hornos de tostación cuya forma era distinta de los hornos de fundición (fornax in qua panes aerei torrefacti coquuntur)). Si nuestras consideraciones son acertadas tendríamos que el área $\mathrm{B}$ y parte de la C corresponderían a zonas de tostación de mineral. Su situación alrededor de una zona abierta tendría sentido para que no hubiera concentración de humos sulfurosos.

En la zona Suroeste se encuentran junto a la puerta de entrada del patio una serie de unidades estratigráficas murarias que forman un compartimento estrecho transversal al muro (1), con unas dimensiones de 3,5 m de largo y 1,20 de anchura. Los dos muros paralelos no parecen cerrar en el muro maestro del edificio y dejan un pequeño hueco ( $\mathrm{fi}-$ gura 4). Junto a ellos se encuentra un espacio que comparte ciertas similitudes con él (3), tampoco muere en el muro perimetral del edificio, aunque su desarrollo en ángulo le confiere un aspecto de habitáculo al que se entraba por un pequeño vano, de dimensiones parecidas a los registrados en las estancias 21 y 22 del sector B. Este cubículo tiene unas dimensiones de $3 \mathrm{~m}$ de ancho y 3,5 $\mathrm{m}$ de lago. En el lado opuesto nos encontramos con otro espacio cerrado de forma acodada, de $2,75 \mathrm{~m}$ de ancho. En esta zona del edificio el Sondeo 1 nos ha aportado materiales que indican que eran espacios domésticos, en especial la estancia 3 , en la que han aparecido cerámicas finas de mesa, cerámicas comunes, y vidrios.

Los lados Norte y Oeste del edificio son en los que se agrupan el mayor número de estancias (figura 4). A pesar del estado fragmentario en que han llegado hasta nosotros cada una de las estancias, pueden proponerse una serie de observaciones de cara a intentar diseccionar estos espacios. En primer lugar, si hemos defendido que el lado Este y parte del Sur del patio no presentan esos apiñamientos de habitáculos y su funcionalidad a partir de los paralelos sugieren un uso relativo a la concentración de los minerales que salían en bruto de las galerías, por sus características habría que considerar que estas áreas sirvieron de unidades de almacenamiento y vivienda.

Cabe hacer una distinción en estas crujías del edificio, pues un muro puede hacer las veces de medianía entre los sectores Norte y Oeste. Por otra parte, en ambos sectores existen recorridos distintos desde el área abierta del patio (17).

La entrada al ala Oeste del edificio (D) se realiza por un vano próximo a la esquina Suroeste, cerca de la puerta del lado Sur. Esta entrada da acceso a una habitación de planta rectangular (4) de $10 \mathrm{~m}$ por $3,5 \mathrm{~m}$, desde la que se abren dos vanos, uno a una estancia de $3 \mathrm{~m}$ por $2,75 \mathrm{~m}$ (13) y otra más amplia de $6 \mathrm{~m}$ por $3 \mathrm{~m}$ (14). No hay un espacio vertebrador de los ejes de esta parte del edificio, como pudiera ser una estancia que a modo de atrio sirviera para articular la comunicación de los espacios. Son comunes los espacios dobles que parecen formar parte de un mismo ambiente. Así se presentan las ya reseñadas estancias 13 y 14, separadas, pero comunicadas por un pequeño vano y ambas en conexión con una estancia que las precede (4). Este mismo esquema adoptan las estancias 5 y 6 , separadas por un muro, pero unidas por un vano, y que acaban en un pequeño pasillo ciego a modo de ala. La estancia 5 tiene unas dimensiones de $4,50 \mathrm{~m}$ por 1,30 $\mathrm{m}$, y la habitación 6 tiene mayores proporciones, 4, $50 \mathrm{~m}$ de largo por $3 \mathrm{~m}$ de ancho. El pasillo al que se accede desde la estancia 6 tiene una anchura de $0,90 \mathrm{~m}$. Otras estancias que parecen tener una relación espacial son la 7 y la 8 , que tienen formas más cuadrangulares y dimensiones muy parecidas. $\mathrm{La}$ estancia 7 tiene unas medidas de $2,90 \mathrm{~m}$ por $3,00 \mathrm{~m}$, y la $82,80 \mathrm{~m}$ por $2,50 \mathrm{~m}$. Del resto de las estancias poco puede comentarse, salvo que están muy destruidas y los muros no tienen continuidad para completar su desarrollo.

En el sector D se encuentra un pequeño sistema de canalización o de evacuación de aguas, que llega al patio después de atravesar las estancias 14 y 4 . En algunos tramos esta cloaca está construida con mampuestos de pizarra u en otros tramos se excavó directamente sobre el substrato.

No pensamos que esta canalización tenga que ver con el tratamiento del mineral, sino con los usos domésticos que le hemos asignado a esta parte del edificio. Es evidente que el agua representa un elemento de suma importancia en las operaciones mineralúrgicas en los yacimientos mineros (Domergue, 2008), pero no creemos que en este caso pueda 
sostenerse que el agua formó parte del proceso de tratamiento de los minerales.

El agua puede afectar a los minerales por su composición, que es un elemento oxidante y tiene capacidad de transformación de los minerales al facilitar su paso desde una fórmula de sulfuros hasta otra de óxido. Este proceso de transformación de los minerales es, sin embargo, una transformación lenta que debe desdeñarse como método de concentración de los metales dentro de la cadena productiva. El agua de las minas que ha tenido contacto con los minerales se transforma en agua ácida, que tiene una gran capacidad de disolución o lixiviación de minerales aptos para ello, como el cobre o el cinc entre otros, y éste es el principio que da origen a la formación del enriquecimiento supergénico en los yacimientos minerales. Con la oxidación de los minerales el agua se convierte así en un agente transportador de los minerales, que pueden precipitarse en condiciones favorables naturales (cementación natural) o artificiales, cuando algún elemento favorece la sedimentación, como el óxido de hierro (ce- mentación artificial). En los dos casos el agua debe finalizar su recorrido en unos depósitos de almacenamiento donde pueda precipitarse, por lo que hay que descartar que esta canalización tenga que ver con un proceso mineralúrgico relacionado con la metalurgia del cobre, pues no se han documentado tanques de lixiviación ni de precipitación.

El agua también puede ser empleada simplemente en un proceso de lavado para eliminar elementos no deseados de la ganga, pero esto también supone un proceso de concentración que debe tener en consideración que hay elementos que pueden desecharse si no se emplea un proceso de selección. Este proceso de selección tiene en cuenta la gravimetría de los distintos componentes arcillosos de nulo interés metalúrgico y minerales terrosos de buen tenor metálico. La diferencia de peso de ambos componentes puede ser útil para que en un proceso de decantación los elementos más pesados, los metales, queden retenidos en el fondo, mientras los más ligeros sigan la corriente del agua. Esta manera de decantación por gravimetría es muy empleada
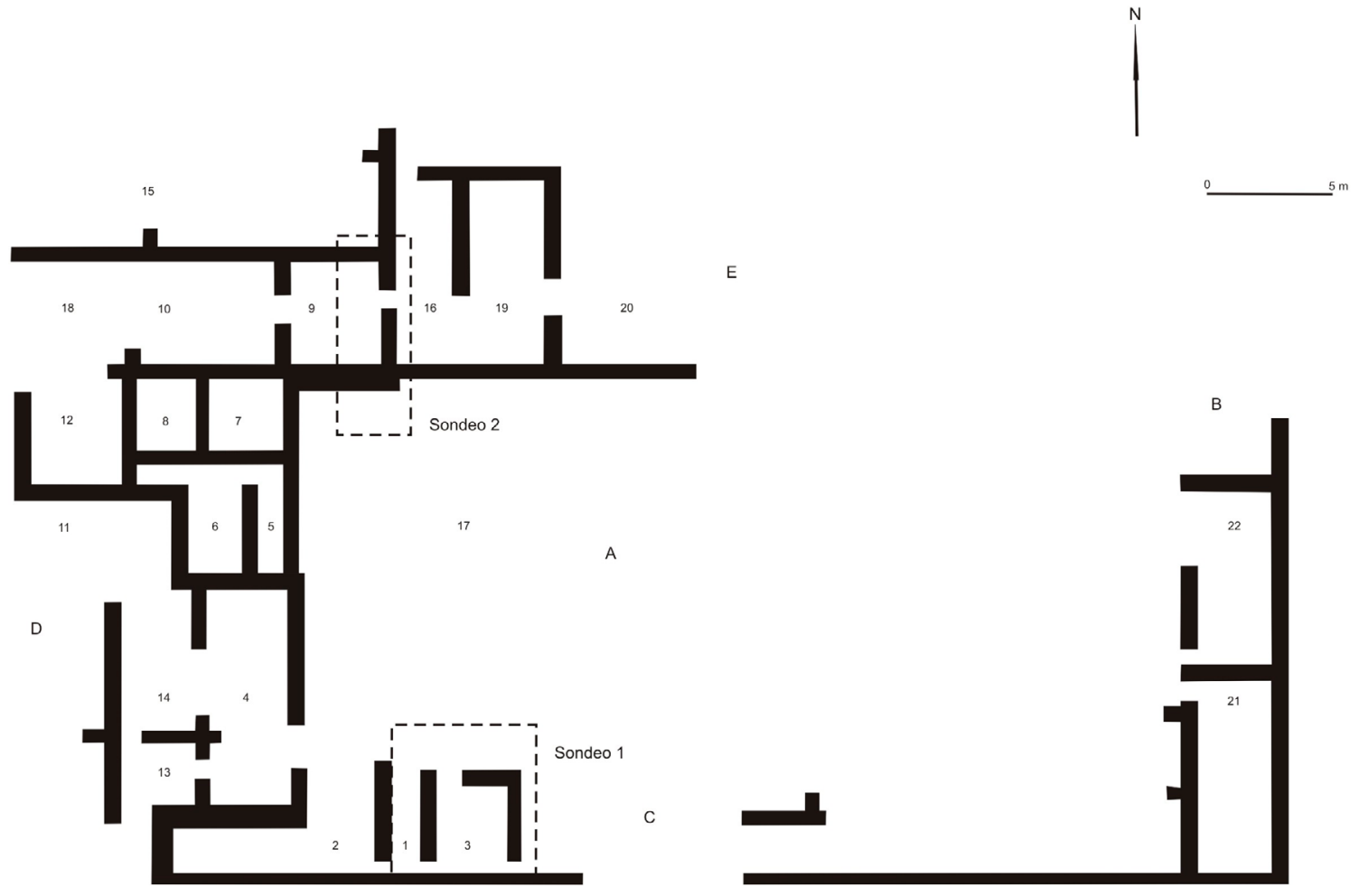

Figura 4. Estructura romana de Aguas Teñidas. 

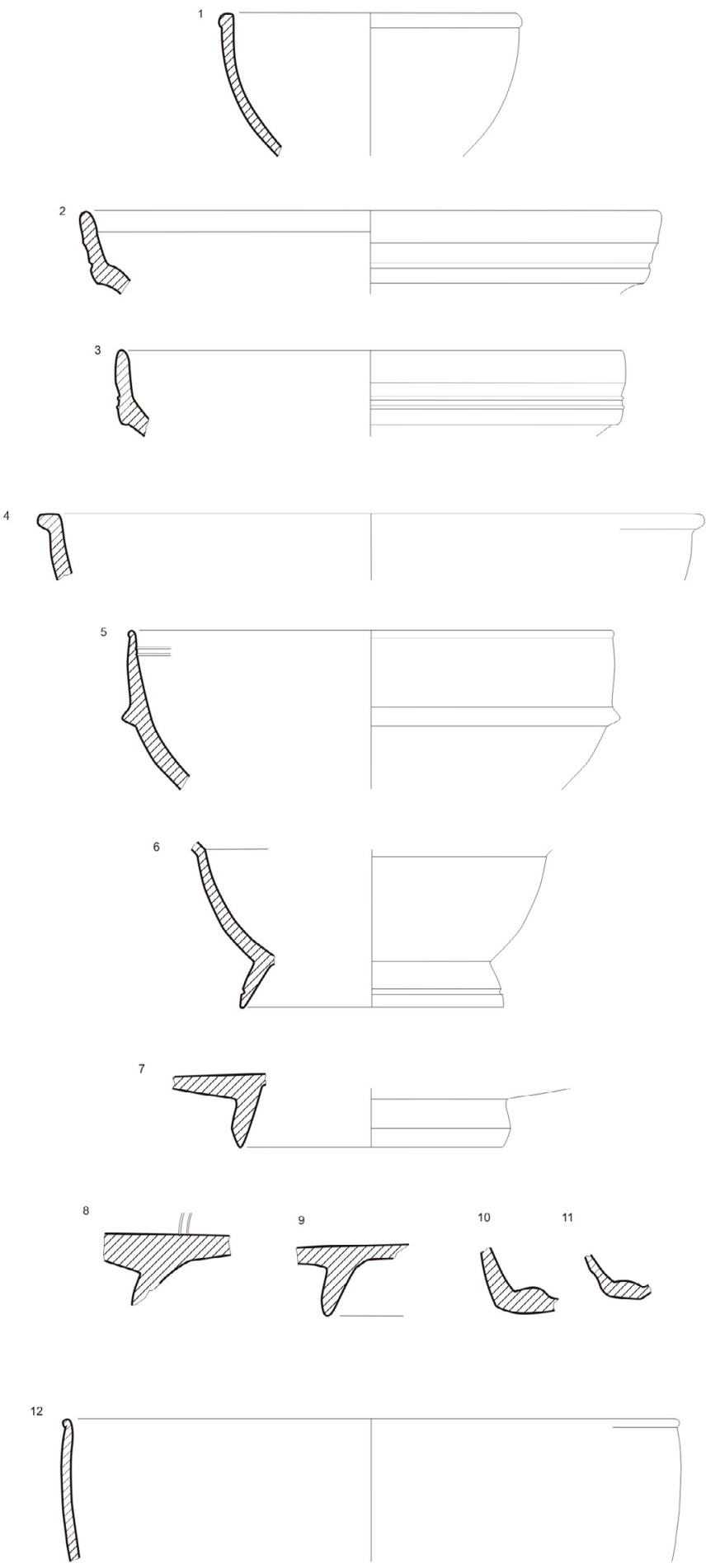

Figura 5. Sigillatas y Paredes Finas. 

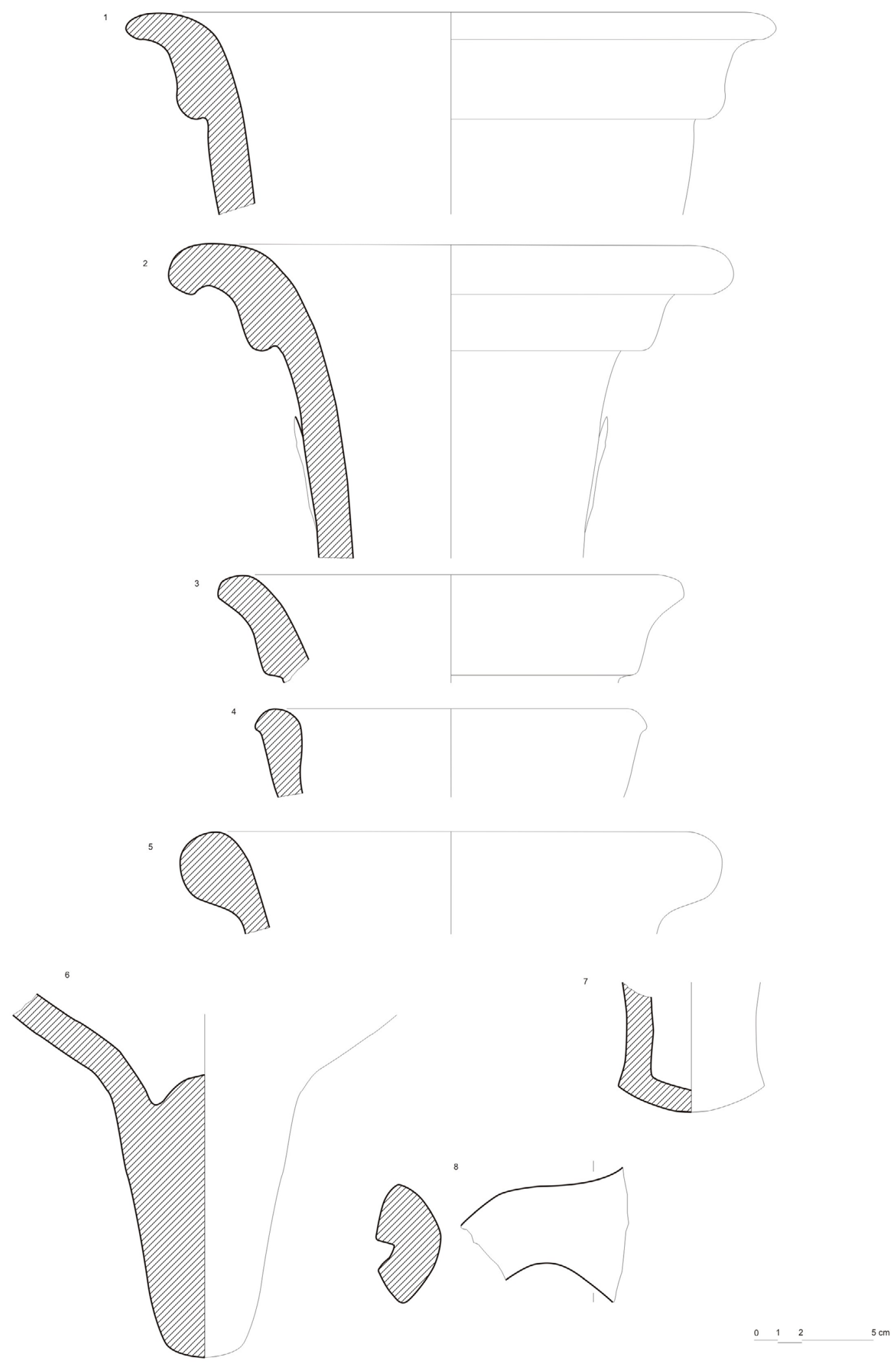

Figura 6. Ánforas.

Revista Onoba, 2013, Nº 01 
en la minería para la concentración de los minerales, pero necesita, como los procesos de precipitación/cementación, de depósitos de decantación, y ello nos lleva a desechar de nuevo la relación de esta canalización y el edificio de Aguas Teñidas con una oficina metalúrgica en la que se emplearon procesos hidrometalúrgicos en el tratamiento de los minerales de cobre.

La disposición cercana de los escoriales romanos puede servir de argumento a este propósito, ya que es un hecho cierto que el agua es un elemento que siempre aparece asociado a los escoriales romanos en las minas de la Faja Pirítica, cuyas instalaciones de fundición y vertederos de escorias se sitúan en época romana, siempre que es posible, junto a cauces de agua, en arroyos y barrancos. Pero esta circunstancia tiene que ver con el enfriamiento más rápido de las lupias de escorias, para que pueda continuar el proceso de fundición con la construcción de nuevas estructuras de reducción y la eliminación de las tortas de escorias alojadas en el hoyo de las escorias. Los hornos constan de dos partes fundamentales, la cámara de reducción y el hoyo donde se va alojando la escoria de sangrado. La estructura del horno es una cámara de mampostería con una

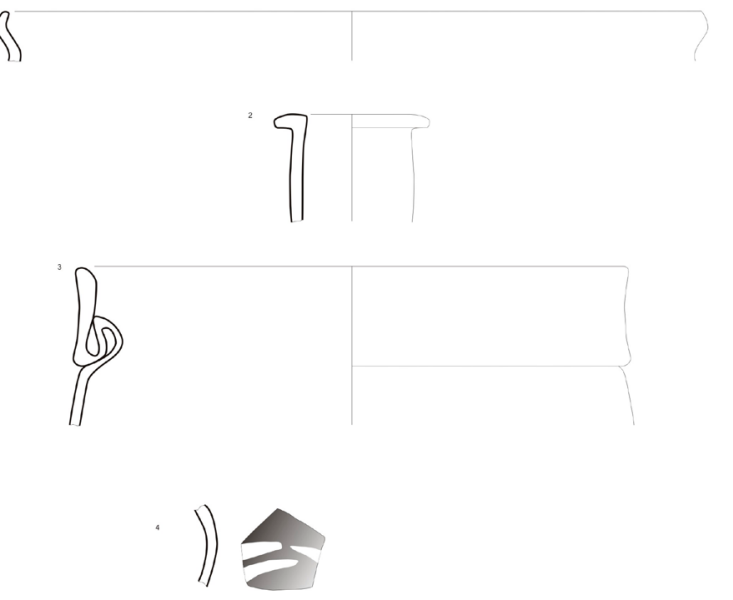

Figura 7. Vidrios. capa interior de arcilla refractaria (camisa del horno), que debe destruirse después de una operación de reducción para poder extraer el lingote que se encuentra en su base (crisol del horno), donde se ha ido depositando el metal por gravimetría, mientras el hoyo de las escorias, situado a una cota inferior a la cámara de reducción, para facilitar la salida de la escoria, se construye excavando la cavidad en el substrato, y la eliminación de la escoria es necesaria para que al construir una nueva cámara de reducción vuelva a acoger la escoria de una nueva fase de reducción. Por eso los escoriales romanos de Aguas Teñidas se encuentran en la margen izquierda del Arroyo de Herrerito, pues con ello se facilitaba un enfriamiento rápido para extraer la lupia.

En los ámbitos de viviendas estas canalizaciones tienen que ver con la eliminación de las aguas pluviales de los patios, atrios o peristilos, y ésta es la funcionalidad que atribuimos a este canal en el edificio de Aguas Teñidas. Esto validaría que esta zona oeste donde se encuentra sea de vivienda, que como es habitual en la edilicia doméstica romana tendría un pequeño patio de luces o atrio que quedaría fuera de la zona intervenida. La canalización evacuaría el agua de lluvia desde ese patio hacia el corral central de la edificación (17).

En la zona Norte del edificio (E) la planta de las estancias está menos completa, pero tiene una más fácil lectura (figura 4). Desde una habitación rectangular de grandes dimensiones (20), se establece un eje longitudinal que va relacionando toda una serie de estancias comunicadas por un vano central. En primer lugar se encuentra otra estancia doble, con dos cuartos, la estancia 19 de $7 \mathrm{~m}$ por $3 \mathrm{~m}$, contigua a otro espacio similar, la estancia 10 , de 4,30 $\mathrm{m}$ por $5,70 \mathrm{~m}$, y finalmente las estancia 18 , de 3,90 $\mathrm{m}$ por $4,40 \mathrm{~m}$, que parece formar parte de ese mismo espacio en forma acodada con la estancia 12 , de $3,40 \mathrm{~m}$ de ancho, pues no existen vanos entre ellas. En una zona no excavada se delimita también una gran estancia bipartita (15), de 3,30 m de ancho, con dos tramos, uno de $9 \mathrm{~m}$ de largo y otro de $5 \mathrm{~m}$. en esta zona es donde estaba situado el Sondeo 2, sobre las estancias 9 y 16.

Extraña que no hayan aparecido en esta zona Oeste o en los alrededores del patio ningún elemento relacionado con el tratamiento de hierro. Este tipo de instalaciones de carburación y reparación de las herramientas de hierro eran indispensables en los asentamientos mineros, ya que en esta época todo el instrumental minero era de hierro y su re- 

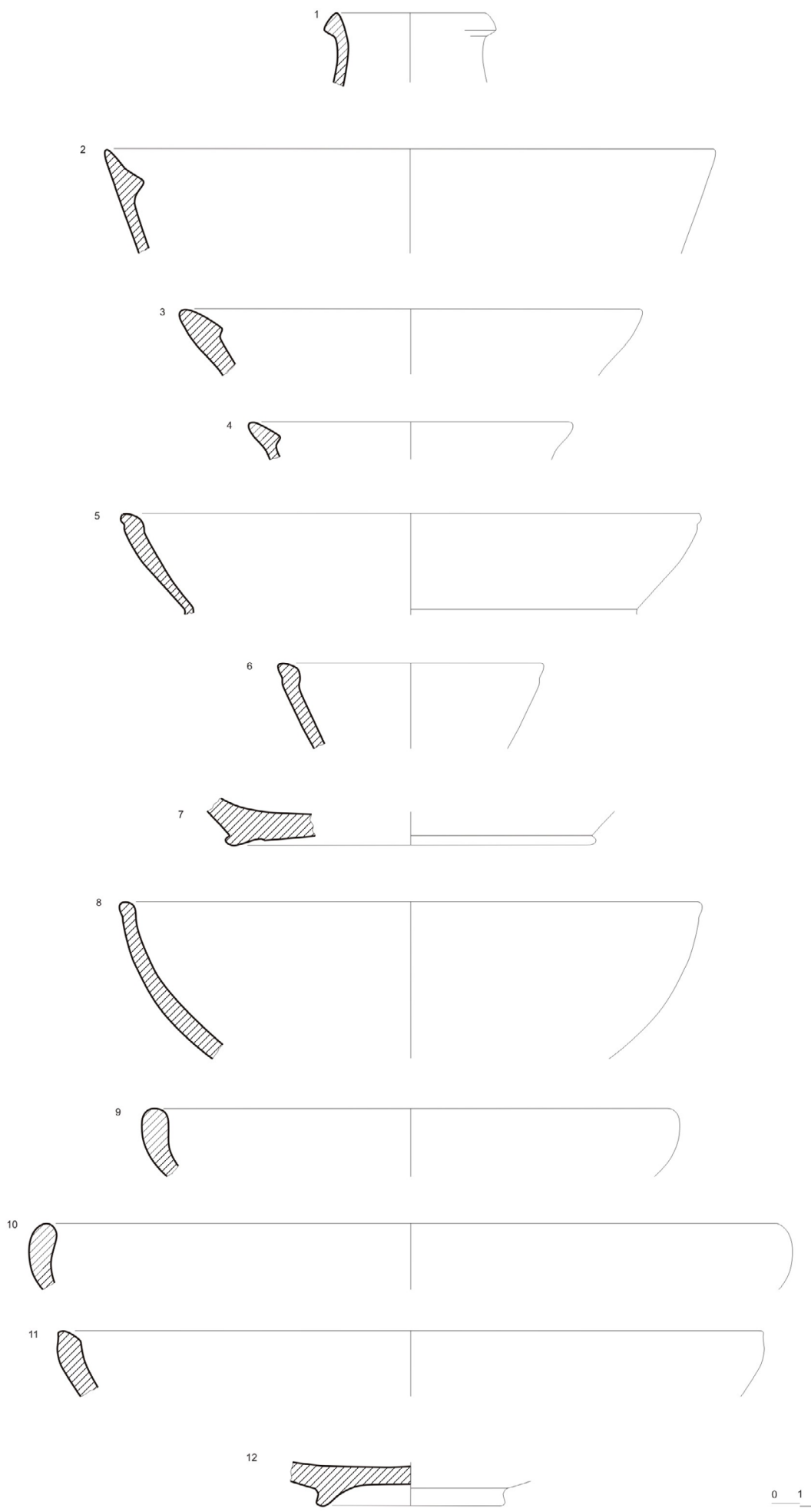

Figura 8. Cerámicas comunes de mesa.

Revista Onoba, 2013, No 01 

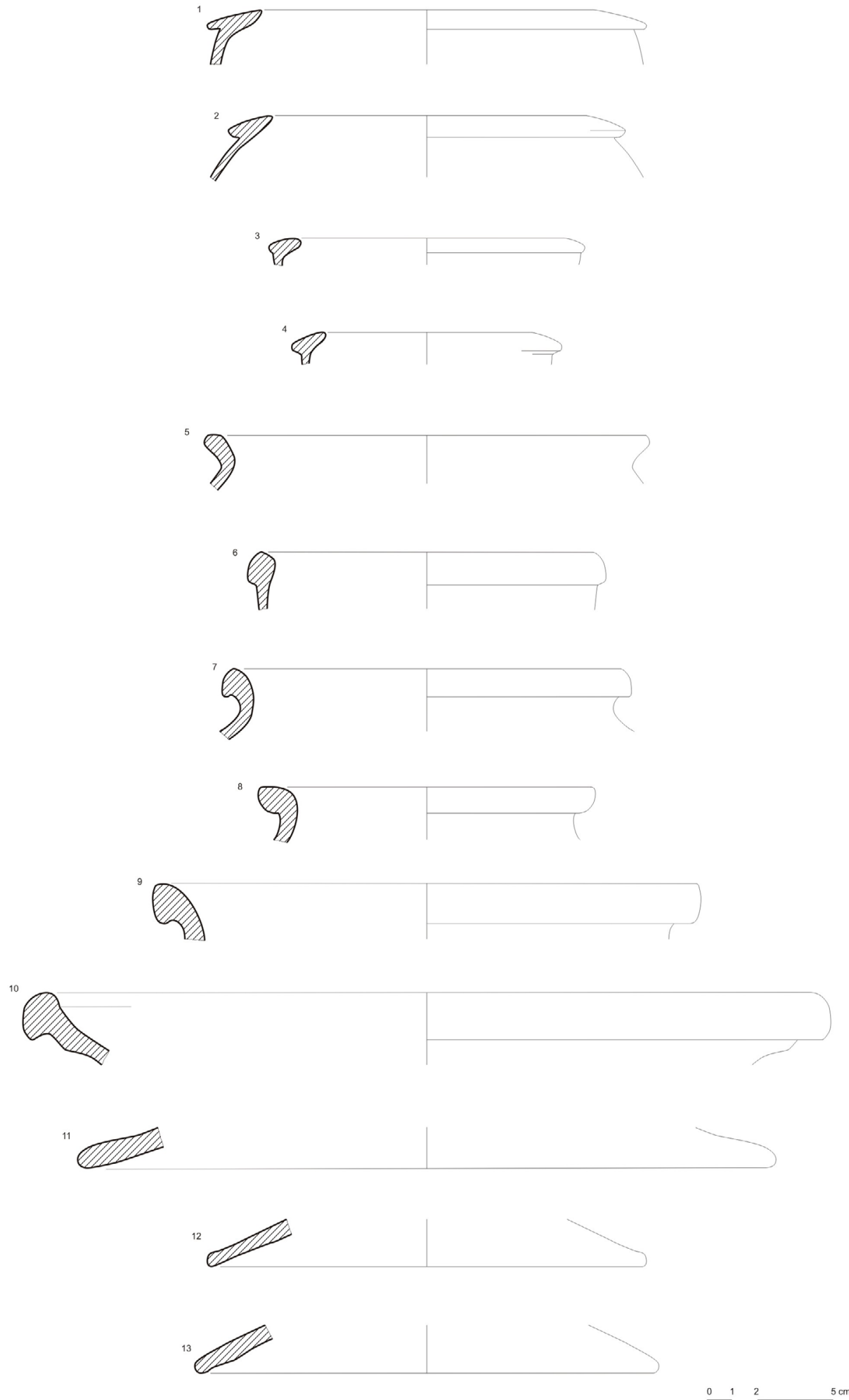

Figura 9. Cerámicas comunes de cocina.

Revista ONOBA, 2013, Nº 01 

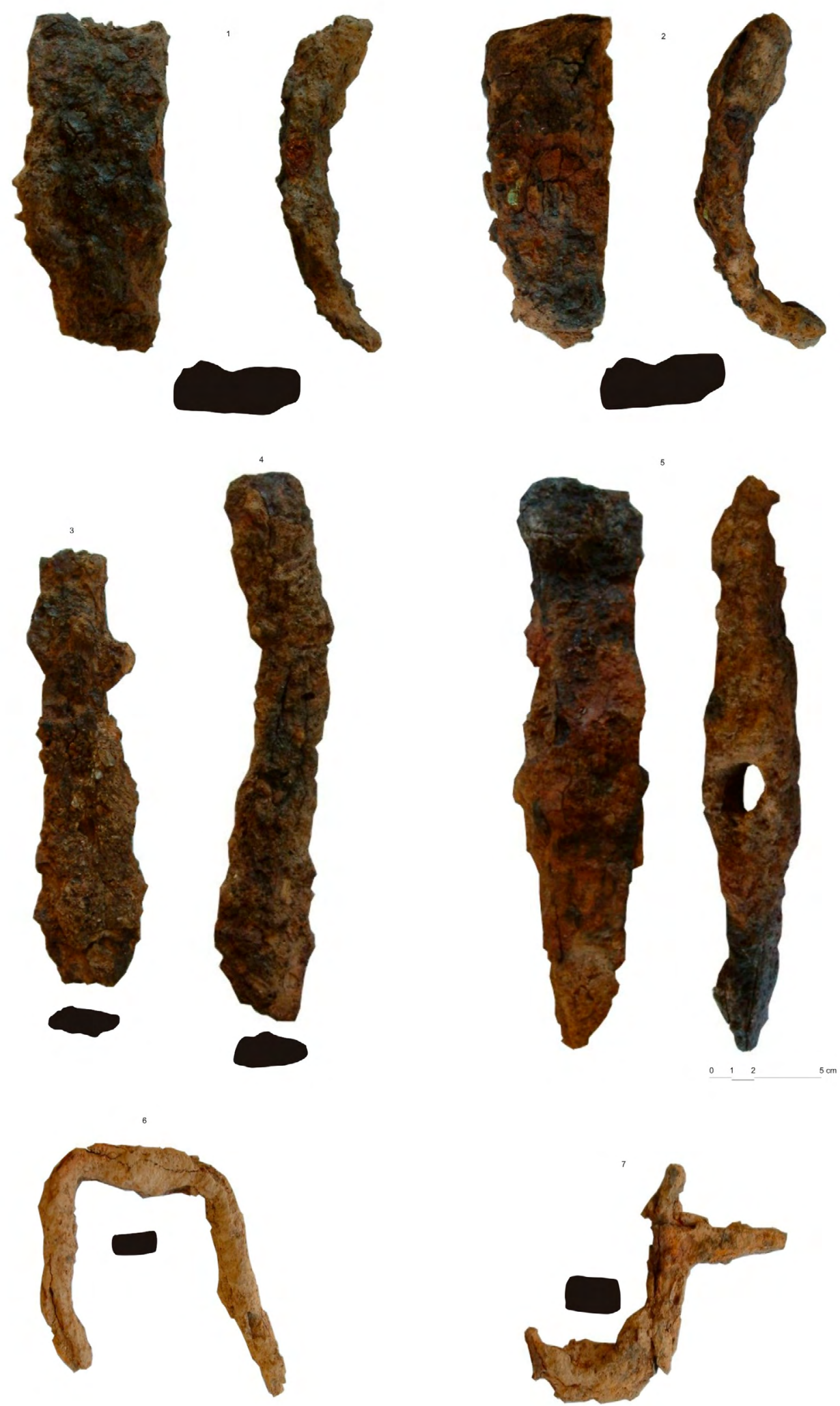

Figura 10. Instrumental de hierro. 
paración obligaba a que en los asentamientos mineros proliferaran las forjas. Así sucede, por ejemplo, en el asentamiento de La Loba (Blázquez, Domergue y Silliéres, 2002). La proximidad de mina de Aguas Teñidas al asentamiento minero de Cueva de la Mora, en el que los análisis de las escorias confirman una pequeña producción de hierro (Blanco y Rothenberg, 1980), aseguraría el abastecimiento de las herramientas que se necesitaban en la mina.

Las estructuras no han aportado gran cantidad de materiales arqueológicos, por lo que el abandono del edificio por la paralización de la explotación supuso el transporte o el traslado de todo el menaje doméstico e industrial, y la escasa presencia de material acumulado a lo largo del período de ocupación induce a proponer un corto período de habitación, como así se desprende además de la estrecha franja cronológica de los materiales cerámicos recuperados en la intervención.

El registro material recogido a lo largo de la intervención ha ayudado a clarificar la funcionalidad de los diferentes sectores y la cronología de la explotación romana en la mina de Aguas Teñidas. Sobre la primera cuestión las cerámicas se encuentran en las áreas Oeste y Suroeste, en las que hemos definido el espacio de vivienda. Entre las estancias en las que se han recogido las especies finas de mesa se encuentran la 1, 2, 3 y 4 . Esta disposición de las cerámicas de mesa que se recogieron en el transcurso de la limpieza superficial no debe servir de orientación, ya que los fenómenos postdeposicionales han podido afectar a la posición originaria de estos materiales. Esta aclaración es indispensable puesto que este tipo de cerámicas han aparecido hasta en la zona abierta de patio, en la que en principio no deberían aparecer. La limpieza superficial se detuvo en cuanto aparecieron las partes superiores de los muros, es decir tras el decapado de las unidades estratigráficas formadas tras la destrucción del edificio. Sólo pueden considerarse los hallazgos de estas cerámicas en los rellenos de las estancias, y eso solo ha podido investigarse en el área reservada a los dos sondeos. De esta forma únicamente tenemos constancia del uso de cerámicas de mesa en las habitaciones 1 y 3 .

Más allá de estas cuestiones de contexto, problemáticas dado el carácter de la intervención, las cerámicas son muy útiles para situar el período de laboreo romano en la mina, y en ello las cerámicas finas de mesa y las ánforas nos permiten aproximaciones bastante fiables. En las primeras se encuen- tran representadas las Sigillatas Itálicas (Ettlinger et al., 2002) y las Sigillatas Sudgálicas (Bemont y Jacob, 1986). Entre las Sigillatas Itálicas se documentan las formas Compectus 19 de época augustotiberiana (figura 5: 2 y 3), y algunos producciones tardoitálicas, como Compectus 36 (figura 5: 1) y Conspectus 37 (figura 5: 4). En las Sigillatas Sudgálicas se encuentran formas claudio-neronianas, Drag. 24/25 y Drag 26/27 (figura 5: 5 y 6), y faltan por completo formas de época Flavia (Vernhet, 1976). Estas cerámicas nos ofrecen una primera aproximación cronológica al asentamiento romano de Aguas Teñidas, entre los principados de Tiberio y Nerón, un momento de explotación que está en consonancia con los tonelajes de escorias de las escombreras romanas de fundición. A esta cronología remite también la cerámica de Paredes Finas, de la que se ha recogido un fragmento de copa de la forma Mayet XXXVII con decoración exterior de arenilla (figura 5:12), de producción bética y cronología claudia (Mayet, 1975).

Las ánforas son de los tipos que aparecen en los contextos mineros del Suroeste ibérico en esos años, las ánforas salsarias de la Bahía de Cadiz (García Vargas, 1998), de la familia Dressel 7/11 (figura 6: 1, 2, 3, y 7), de defruto de la Baja Andalucía (Carreras Monfort, 2003), las ánforas Haltern 70 (figura 6: 4, 6 y 8), y de aceite del valle del Guadalquivir (García Vargas, 2001), la forma Dressel 20 antigua (figura 6:5).

Dentro de las cerámicas comunes se encuentran las especies de mesa y cocina. En las de mesa abundan algunas formas de cuencos hemisféricos de borde engrosado o indicado (figura 8: 8 a 11), y jarras de boca abocinada de borde escalonado al interior (figura 8: 2 a 4), unas formas corrientes en el siglo I d.C. (Vegas, 1969) y con paralelos en el cercano asentamiento minero de Cerro del Moro (Nerva) en el distrito de Riotinto (Pérez y Delgado, 2007). En las especies de cocina predominan las ollas de borde de martillo (figura 9:1 a 4), las ollas de borde saliente (figura 9: 5), las ollas de borde vuelto (figura 9: 7 a 9), y no faltan los mortaria (figura 9: 10) y los opercula (figura 9: 11 a 13).

En estos materiales domésticos se incluyen también vasos de vidrio, formas 32 (figura 7: 1), 28 (figura 7:2), y 37 (figura 7:3) de la tipología de Isings (1957), un fragmento de vidrio con pintura blanca (figura 7:4), y una ficha de juego de pasta vítrea (figura $7: 5$ ). 
En la excavación del Sondeo 1 aparecieron objetos de hierro muy corroídos. Entre ellos varios en forma de espuela, que podrían ser abrazaderas para maderas de portajes o ventanas (figura 10: 6 y 7), posibles gubias (figura 10: 3 y 4), una dolabra (figura 10: 5), herramienta muy apropiada para las tareas de entibación y fortificación de las labores, y otros objetos de difícil clasificación (figura 10: 1 y 2). Entre los objetos metálicos se encuentran asimismo un fragmento de pesa de plomo, un pequeño aro de bronce, y parte de una espátula de bronce.

No encontramos ningún elemento que nos haga sospechar que esta edificación tuvo un carácter industrial, y debemos plantear que, a la falta de otras estructuras que lo acompañen, este edificio cumplía las funciones de vivienda y almacén junto a las zonas de tratamiento metalúrgico. Si relacionamos la extensión del edificio con la cantidad de personas que pudieron vivir en él resulta complicado llegar a la conclusión que todas las labores de la mina pudieron haberse efectuado por un grupo reducido de operarios, ya que en ningún caso este edificio podía albergar a más de 20 personas, incluso en el caso de que en cada instancia pudieran convivir más de dos, como ocurre en las barracas de los acuartelamientos. Desde este punto de vista es evidente que nos encontramos ante un tipo de hábitat minero completamente diferente al conocido en las grandes minas de la Faja Pirítica, como el de Cortalago/Llano de los Tesoros de Riotinto, Pueblo Nuevo de Tharsis, o Casa do Procurador/Lavaría en Aljustrel. Estos poblados son grandes aglomeraciones urbanas, con unas dimensiones que en todos los casos superan casi los $2 \mathrm{~km}$ de longitud.

Estas estructuras ocupan un área mínima de unos 1513 metros cuadrados, que corresponden a una sola edificación en la que se han delimitado al menos 23 estancias. A pesar de que una parte del edificio ha podido estar destinado a uso como vivienda, para los funcionarios encargados de la gestión de la fodina, el espacio que estaría dedicado a esta función no es suficientemente amplio como para pensar que todo el personal que trabajaba en la puesta en explotación de esta mineralización tendría cabida en el edificio. Entre este personal se encontrarían los mineros que trabajaban y arrancaban el mineral, los técnicos en las operaciones mineralúrgicas que permitían la producción de cobre metálico, y aquellos funcionarios que se encargaban de la administración diaria de estas operaciones, de anotar los cargamentos de metal, de asegurar el abasteci- miento y de la seguridad de las instalaciones. Todo ello hubiera obligado a la construcción de cuarteles mineros junto a la mina, pero de ello no queda ninguna huella. Es posible que dada la cercanía del poblado de Cueva de la Mora, los trabajadores se trasladaran desde allí a la mina de Aguas Teñidas, y que por esto ella solo se construyera este edificio para satisfacer las necesidades de tratamiento y almacenamiento de los productos. Hay que partir del hecho de que el sistema de administración romano en la mina permitía una gestión indirecta de la producción metálica, que se dejaba en manos de concesionarios particulares (socii o conductor), que solo estaban sujetos a las condiciones exigidas por la administración imperial, el respeto y mantenimiento de las obras de infraestructuras comunes, como las galerías de desagüe y las entibaciones, y a satisfacer los pagos en mineral que correspondían al fisco.

$\mathrm{La}$ arquitectura de este edifico, con estructuras en torno a un área abierta, es corriente en los talleres metalúrgicos, tanto en las officinae urbanas o periurbanas (Gralfs, 1988), como en las fabricae de los acuartelamientos militares (Bishop, 1985). Sus paralelos se encuentran también en el mundo rural, donde está presente en las villas de gran patio rodeadas por espacios de producción, almacenamiento y vivienda, que se hacen corrientes a partir de época tardorrepublicana (Gros, 2001). Incluso el corral en torno al cual se levantan los distintos sectores del edifico es el elemento fundamental de las stationes de los caminos (Chevallier, 1997). No es por tanto un tipo de edificación específico de la explotación minera, tiene paralelos en todos los sectores de la economía del mundo romano. Es una edificación de grandes proporciones en la que debían reunirse todos los espacios que eran precisos para el tratamiento del mineral, el almacenamiento, y la vivienda.

La mina de Aguas Teñidas no tuvo una producción tan importante como para que se pudiera fijar población en sus alrededores, más aún estando tan cerca el poblado de Cueva de la Mora, desde el que se aseguraba el abastecimiento, y con este edificio se cubrían las necesidades a pie de mina. El mineral podía estar a resguardo a la espera de su tratamiento, seleccionarse y apartarse en razón de su calidad, y se fundía fuera de la instalación, evitando de este modo el traslado de las lupias de escoria incandescentes. El edificio tenía también capacidad para ser la residencia de los funcionarios que gestionaban la marcha de los trabajos, y servía de almacén para los 
instrumenta que se utilizaban en la mina, desde el arranque hasta el transporte y la iluminación, y como depósito de aquellos productos alimenticios que llegaban desde el vecino poblado de Cueva de la Mora.

Una cuestión importante es conocer si este edificio fue construido por iniciativa de la administración imperial, para asegurar la correcta fiscalización a pie de mina de la producción del metal, o si por el contrario se levantó por los concesionarios que se hicieron cargo de la mina y la pusieron en explotación. Nuestra opinión es que este tipo de instalaciones debieron ser construidas por los técnicos imperiales en el momento en el que se intuía que la mineralización tenía posibilidades de rendir una buena producción de cobre, y que posteriormente, cuando se concedía la explotación a concesionarios privados, el edificio era la sede de los funcionarios que aseguraban los intereses del fisco en la concesión.

\section{CONCLUSIONES}

Este edificio romano de Aguas Teñidas define a nuestro modo de ver la diversidad de modelos de explotación en las minas romanas de la Faja Pirítica Ibérica, en la que se han contabilizado más de 100 yacimientos de sulfuros con señales de explotación de este período. Este hecho ilustra claramente la capacidad de la ingeniería romana en la exploración de los yacimientos a partir de evidencias superficiales, en ocasiones mínimas, como es el caso de Aguas Teñidas, cuya delación solo pudo llevarse a cabo por leves coloraciones ferruginosas o por los sulfatos de hierro disueltos en las aguas, que acabaron por dar nombre a la mineralización.

A grandes rasgos pueden establecerse dos grupos dentro de estos yacimientos de sulfuros, aquéllos que estaban formados por varias masas y aquellos otros con un solo depósito de sulfuros. La idea general que se obtiene cuando se repasa la historiografía de la minería romana en la Faja Pirítica es que son minas con inmensas reservas, y ello es cierto si comparamos a estos yacimientos con las estructuras filonianas de sulfuros de plomo o de cobre de la zona Ossa Morena. En esta última zona geológica la potencia de los filones en raras ocasiones sobrepasa el metro de espesor, y dentro de la veta la ley de mineral todo-uno es baja. Por el contrario, en las minas de la zona Surportuguesa (Faja Pirítica) los minerales se presentan formando grandes masas polimetálicas que en ocasiones pueden alcanzar más de un $\mathrm{km}$ de extensión y cubicajes de miles de toneladas. En todo caso, aunque la proporción de minerales sea de mayor envergadura en estos grandes depósitos, también hay que tener presente que los rendimientos y posibilidades de beneficio no eran iguales en minas que contaban con una sola masa de mineral y en aquellas otras en las que el metallum estaba formado por más de una masa.

A modo de ejemplo pueden señalarse los cotos mineros más importantes de la zona, Riotinto, Tharsis o Aljustrel. En el primero fueron explotadas las siguientes masas, Lago, Salomón, Dehesa y Mal Año en el costado Norte de la Sierra del Mineral, y Filón Sur, San Dionisio y Planes en el costado Sur. La minería romana fue más intensa en las masas de la zona norte, donde existían mayores enriquecimientos en minerales de plata, y este metal fue la verdadera guía de la explotación romana. En Filón Sur y masa Planes, sin esos niveles de minerales jarosíticos ricos en plata, la minería no alcanzó esas cotas de extracción y se centró en la explotación de los minerales de cobre, de menor interés a juzgar por la diferencia de toneladas entre los escoriales de plata de la zona Norte y los escoriales de cobre de la zona Sur. Con estas perspectivas se entiende que el principal asentamiento minero, Llano de los Tesoros/Cortalago (Jones, 1980; Luzón y Ruiz, 1975; Blanco y Rothenberg, 1980), se extendiera a lo largo de las masas de la zona Norte, desde la de Mal Año y Dehesa hasta la de Lago, mientras en las otras masas solo existieron pequeños poblados relacionados con la explotación de una masa, como sucede en el caso del poblado de Marismilla junto a la masa Planes (Pérez y Delgado, 2012). Pero incluso en este último ejemplo estamos ante un asentamiento de cierta extensión, al que corresponde un área de necrópolis bien definida. Un modelo similar es el que nos muestra la mina de Tharsis, con las masas de Filón Sur, Filón Norte, Poca Pringue, Filón Centro, y Sierra Bullones, y el hábitat centrado en la masa con minerales de plata, la de Filón Sur, aunque no se descuidó la producción de cobre (Sierra Bullones y Filón Norte) y plata (Filón Centro) en el resto de las masas (Domergue, 1990; Pérez, Martins, Bustamante, y Delgado, 2009). En Aljustrel la masa más beneficiada fue la de Algares para la explotación de los minerales de cobre, pero la minería se prolongó a lo largo de toda la época imperial (ss. I al V d.C.), en la que se fue configurando un extenso hábitat a uno y otro lado del Morro de Algares (Domergue, 1983; Parreira, 1982; Martins, Pérez, Baptista, Bus- 
tamante, y Lagares, 2012), completamente rodeado, como en los casos de Riotinto y Tharsis, por inmensos escoriales.

Estos tres asentamientos debieron ser grandes aglomeraciones, en las que se centralizaba la vida de los territorios de los alrededores, el lugar donde residían los funcionarios imperiales, donde se encontraban algunas officinae que elaboraban productos para todo su distrito minero, y desde los cuales se mantendría abastecidos a los diferentes poblados de la zona. A esto hay que sumar que en sus alrededores, a veces a menos de $5 \mathrm{~km}$ de distancia, se encontraban otros yacimientos mineros que dependían administrativamente de ellos. Próximas a Riotinto se encuentran las minas de Peña de Hierro, Poderosa, etc., y a las de Tharsis las minas de Vulcano, Almagrera, Prado Vicioso, Lapilla, etc. En todas estas pequeñas minas se encuentran huellas de la actividad romana en forma de minados de exploración y explotación, y escoriales que demuestran que el laboreo romano acabó generando producción metalúrgica. Pero las evidencias de poblamiento son más reducidas, no alcanzan las manifestaciones de los grandes poblados de Riotinto, Tharsis o Aljustrel, y en muchas ocasiones no se han documentado restos de hábitat. Esto es una prueba de que sus lugares de habitación eran simples viviendas con cubiertas de ramajes y que el período de ocupación fue tan corto que no han dejado acumulaciones estratigráficas con suficiente potencia como para ser detectadas.

No se conocen muchos poblados de estas características debido a que la investigación se ha centrado preferentemente en los grandes yacimientos, donde las excavaciones y prospecciones arqueológicas han ido en casi todas las ocasiones a remolque de la minería contemporánea, bajo la fórmula de actividades de urgencia o preventivas. Determinar así la fisonomía y las características urbanísticas de los asentamientos de estas pequeñas minas es una tarea de dudoso éxito, aunque pueden plantearse algunas cuestiones generales, de las que el yacimiento romano de Aguas Teñidas nos ofrece nuevas luces.

Estas pequeñas minas destacan por sus cortas ocupaciones, una conclusión que puede obtenerse tanto del análisis de los escasos restos constructivos, que reflejan que fueron yacimientos muy efímeros, como de la envergadura de los escoriales, que son el resultado de una explotación que no se extendería más allá de una decena de años. Son, por otro lado, asentamientos que surgieron en la época en la que se desencadenó la fiebre minera del cobre, sobre todo a partir del principado de Augusto y en la primera mitad del siglo I d.C. Tras una intensa explotación que benefició los niveles más rentables de la zona de enriquecimiento supergénico, una vez agotados se abandonó la explotación sin invertir más capital para llevar a cabo una exploración geológica sistemática de las masas minerales y de sus posibles ramificaciones y potencia. Era, como en otros muchos aspectos de la minería romana, un sistema de explotación que primaba el rendimiento rápido, y si no había grandes volúmenes de mineral las inversiones en exploración no se consideraban rentables. La minería de época imperial era una actividad fundamentalmente privada, sometida a las reglas que imponía la legislación minería imperial (Mateo, 2001), pero que anteponía el enriquecimiento a la explotación integral de los yacimientos, y esto se observa en que una vez que se paraliza la explotación de una mina, rara vez volvían a emprenderse trabajos de exploración, pues ningún concesionario de minas veía ya posibilidades de éxito en una explotación que había cesado por falta de expectativas de rendimiento. Todo parece indicar que sólo en los grandes yacimientos, con masas minerales que se extendían en centenares de metros, podían arriesgarse nuevas inversiones.

En este esquema de poblamiento de las minas del Suroeste ibérico es en el que podemos insertar la explicación de la statio excavada en la mina de Aguas Teñidas. En un área de menos de $20 \mathrm{~km}$ alrededor de esta mina se encuentra un grupo de concesiones, ya explotadas en época romana (Pérez Macías, 1998), que ilustran el interés que mostró Roma en la explotación sistemática de este territorio. Las más cercanas son las de Herrerías de los Confesionarios (Valdelamusa), Cueva de la Mora, la principal mina de la comarca si atendemos al volumen de escorias que se depositaron en los alrededores (Blanco y Rothenberg, 1980), la de Monte Romero, que había sido una importante explotación para plata y cobre en época protohistórica (Blanco y Rothenberg, 1980), y Angelita. Algo más alejadas se encontraban las minas de San Telmo, El Carpio, Lomero, Poyatos, Lancha-Roma, y La Joya. La proximidad de unas minas a otras facilitaba que se pudiera formalizar un distrito a parte de los de Riotinto y Tharsis. Desde el punto de vista de los materiales, en este grupo destaca, como acabamos de señalar, la mina de Cueva de la Mora, cuya producción estaba diversificada para la producción de plata y cobre. 
Monte Romero y Angelita no tuvieron una producción significativa si hemos de ponderar sus escoriales. Es decir, la única mina que interesó para su explotación fue la de Aguas Teñidas, apenas a $2 \mathrm{~km}$ de Cueva de la Mora, de la que debía depender. Sería precisamente la explotación de Cueva de la Mora la que fijó la atención en estas minas, lo que favoreció la exploración de Monte Romero y Angelita, que no ofrecerían buenos resultados, y de Aguas Teñidas, donde se descubrieron buenos enriquecimientos en cobre que dieron lugar a su explotación. La exploración también tuvo éxito en San Telmo, donde existe un pequeño escorial de escorias de plata, El Carpio, con algunos mantos de escorias de cobre, y la Joya, con otro escorial de cobre, pero tendría poca fortuna en Roma y Lomero-Poyatos, en las que solo existen algunos montones de escorias producto de fundiciones de bondad para conocer la calidad de sus minerales. Lo curioso es que Lomero-Poyatos es una mina que se ha destacado por sus proporciones de oro, de 2 a 4 gramos a la tonelada, una mena que puede rentabilizarse en la actualidad, pero imposible de detectar y separar para la ingeniería romana. Salvo en Cueva de la Mora, en la que la masa mineral tenía mayor envergadura, en el resto de las minas no parece que la explotación romana fuera muy prolongada, y los asentamientos romanos son difíciles de detectar debido a la precariedad de las instalaciones. En Cueva de la Mora los restos del hábitat romano se extendieron entre el Arroyo de la Juliana y la masa mineral, y al fin y al cabo fue el único asentamiento que perduró en el tiempo, después de que la exploración consideró agotadas y paralizó el trabajo en las pequeñas masas minerales que se encontraban en los alrededores.

Desde esta perspectiva, el asentamiento de Aguas Teñidas puede ser considerado como un modelo de lo que ocurrió en otras minas del Suroeste peninsular. Hasta el momento centrábamos nuestra investigación en los restos de minería que se habían descrito por J. Gonzalo y Tarín e I. Pinedo Vara, en la analítica de las escorias para conocer a qué proceso productivo estaban asociadas, y al estudio de los materiales cerámicos que aparecían en estos escoriales, que nos ofrecían las pautas cronológicas del período de laboreo metalúrgico de las minas. Asumimos que en todas las minas la explotación romana se ajustaba a los mismos parámetros o bien no considerábamos que la explotación no siempre siguió el mismo ritmo. El asentamiento de Aguas Teñidas nos demuestra que cada mina, por sus ca- racterísticas geológicas, debió representar un modelo particular. Si bien parecen intuirse comportamientos generales en todos estos distritos mineros del Suroeste, como es la escasa atención que merecieron de la minería republicana, sólo testimoniada en Riotinto. Después de la exploración minera que se desencadenó a partir de época tardorrepublicana, la historia de cada mina parece adaptarse a sus posibilidades. Unas fueron intensamente exploradas y no se consiguió localizar la masa de mineral, como nos muestra el caso de la mina de Cabezas de los Pastos (Puebla de Guzmán). En otras se descubrieron enormes masas que dieron lugar a una explotación más continuada en el tiempo, entre las que cabe destacar las de Tharsis, Sotiel Coronada, Castillo de Buitrón, Cueva de la Mora, y Aljustrel. Y finalmente en otras se generaron buenas expectativas por la riqueza de sus minerales, pero al cabo de unos años esas zonas de altas leyes estaban agotadas al no haberse volcado la exploración minera en la búsqueda de la continuidad de los yacimientos.

Es en este último modelo en el que debemos encuadrar la mayor parte de las minas de la Faja Pirítica Ibérica explotadas en época romana, pues después de la segunda mitad del siglo I d. C., pasado el esplendor de la explotación julio-claudia, la minería solo tuvo continuidad en las grandes minas. Riotinto, Tharsis, y Aljustrel son por ahora los únicos yacimientos mineros que continuaron a buen ritmo de producción después de mediados del siglo I d.C. Aunque lógicamente la exploración minera pudo continuar en otras comarcas, el resultado nunca fue el esperado. Debemos centrar, pues, el momento álgido de la minería romana en la Faja Pirítica Ibérica en la estrecha franja temporal de último cuarto del siglo I a.C. y mediados del siglo I d.C., y este momento es el que está perfectamente representado en el modelo de ocupación de la mina de Aguas Teñidas.

\section{BibLIOGRAFÍA}

Agricola, G. (1556), De re metallica, Edición de Explosivos Rio Tinto y traducción de C. Andreu, Madrid (1972).

Bazzana, A. y Trauht, N. (2005), "El sector 7, los talleres y los vestigios de una metalurgia medieval”, Excavaciones en la isla de Saltés (Huelva), 1988-2001 (A. Bazzana y J. Bedia García, Drs.), Sevilla, 199-211.

Beemont, C. y Jacob, J.P.-Eds. - (1986), La terre sigillée gallo-romaine. Lieux de production 
du Haut Empire, implantaction, produits, relations, Documents d'Archeologie Française, 6, Paris.

Bishop, M.C. (1985), "The military fabrica and the production of arms in the principate", The Production and Distribution of Roman Military Equipment (M.C. Bishop, Ed.), British Archaeological Report, 275, Oxford, 1-42.

Blanco, A. y Rothenberg, B. (1980), Exploración Arqueometalúrgica de la provincia de Huelva, Barcelona.

Blázquez, J. M ${ }^{\mathrm{a}}$, Domergue, C. y Silliéres, P. (2002), La Loba (Fuente Obejuna, province de Cordoue, Espagne). La mine et le village minier antiques, Bordeaux.

Carreras Monfort, C. (2003), Geografía de la producción de les Haltern 70, Culip VIII $i$ les ámfores Haltern 70, Monografies del Casc, 5, Barcelona, 75-81.

Cauuet, B., Domergue, C., Dubois, C., Pulou, R. y Tollon, F. (1999), "La production de cuivre dans la province romaine de Lusitanie. Un atelier de traitement du minerai à Vipasca", Économie et territorie en Lusitanie romaine, Collection de la Casa de Velázquez, 65, Madrid, 279-306.

Chevallier, R. (1997), Les voies romaines, Paris.

Deligny, E., (1863), Apuntes históricos sobre las minas cobrizas de la Sierra de Tharsis (Tharsis Baetica), Revista Minera, XIV, 111-121.

Domergue, C. (1983), La mine antique d'Aljustrel (Portugal) et les Tables de Bronze de Vipasca, Paris.

Domergue, C. (1990), Les mines de la Peninsule Ibérique dans l'antiquité romaine, Collection de l'École Française de Roma, 127, Roma.

Domergue, C. (2008), Les mines antiques. La production des métaux aux époques grecque et romaine, París.

Ettlinger, E., Hedinger, B., Hoffmann, B., Kenrick, PH. M., Pucci, G., Roth-Rubi, K., Schneider, G., Schnurbein, S., Wells, C.M., y Zabehlicky-Scheffenegger, S, (2002), Conspectus Formarum Terra Sigillatae Italico Modo Confectae, Bonn.

Fernández, M. y García, C. (1993), " La minería de época romana en Sierra Morena, el poblado de Valderreprisa (Fuencaliente, Ciudad Real)", $M e$ langes de la Casa de Velázquez, XXXIX-1, 25-50.

García Vargas, E. (1998), La producción de ánforas en la Bahía de Cádiz en época romana (siglos II a.C.-IV d.C.), Écija.

García Vargas, E. (2001),” Producción de ánforas romanas en el sur de Hispania, República y Alto Imperio" Congreso Internacional Ex Baetica Amphorae, I, Écija, 57-174

Gonzalo Tarín, J. (1888), Descripción física, geológica y minera de la provincia de Huelva, Memorias de la Comisión del Mapa Geológico de España, Madrid.

Gralfs, B. (1988), Metallverarbeitende Produktionsstätten in Pompeji, BAR International Series 433, Oxford.

Gros, P. (2001), L'architecture romaine. 2, Maisons, palais, villas et tombeaux, París.

Isings, C. (1957), Roman Glass from Dated Finds, Groningen.

Jones, B. (1980),” The Roman Mines at Río Tinto”, Journal of Roman Studies, 70, 146-165.

Luzón, J. Mª y Ruiz, D. (1970), "El poblado minero romano de Riotinto", Habis, 1, 125-138.

Martins, A., Pérez, J.A., Baptista, H., Bustamante, M., y Lagares, M. (2012), "Novos achados em Algares (Aljustrel, Portugal). Refleções sobre o vicus Viapscense", V Encontro de Arqueología del Sudoeste, Almodôvar, 393-412.

Mateo, A. (2001), Observaciones sobre el régimen jurídico de la minería en tierras públicas en época romana, Santiago de Compostela.

Mayet, F. (1975), Les céramiques a parois fines dans la Penínsule Ibérique, Paris.

Parreira, R. (1982), "O salvamento arqueológico de Vipasca. Nota preliminar sobre a campanha de escavações de 1981", Arquivo de Beja, $1 / 2^{a}$ serie, 83-106.

Pérez Macías, J.A. (1998), Las minas de Huelva en la Antigüedad, Huelva.

Pérez, J.A., Martins, A., Bustamante, M. y Delgado, A. (2009), "De Praesidium a Vicus Metallum, el poblado minero en el suroeste peninsular", $A n$ dalucía Romana y Visigoda. Ordenación y vertebración del territorio, Roma, 37-64.

Pérez, J. A. y Delgado, A. (2007),"Los metalla de Riotinto en época julio-Claudia“, Las minas de Riotinto en época julio-claudia (J.A. Pérez y A. Delgado, Eds.), Huelva, 37-185.

Pérez, J.A. y Delgado, A. (2012), "El asentamiento romano en el paraje de Marismilla (RiotintoNerva, Huelva)", Paisajes, tiempos y memoria (J.A. Pérez Macías, J.L. Carriazo Rubio y B. Gavilán Ceballos, Eds.), Huelva, 45-82.

Pérez, J.A., Martins, A., Bustamante, M. y Lagares, 
J. (2012), In Abditas Terras. Investigações Arqueológicas em Aljustrel, Huelva.

Pinedo Vara, I. (1963), Piritas de Huelva. Su historia, minería, y aprovechamiento, Summa, Madrid.

Romero, E. y Rivera, T. (2010),”Análisis de la intervención arqueológica en la explotación minera de Aguas Teñidas (Almonaster la Real, Huelva)", Anuario Arqueológico de Andalucia/2006, 1969-1973.

Vegas, M. (1969),"Römische Keramik des 1. Jahrhunderts n. Chr.”, Madrider Mitteilungen, $X, 199-250$.

Vernhet, A. (1976), "Création flavienne de six services de vaiselle á la Graufesenque", Figlina, 1, 13-27. 